\title{
Photochemical Behaviour of Carbamates Structurally Related to Herbicides in Aqueous Media: Nucleophilic Solvent Trapping versus Radical Reactions
}

\author{
Monica Passananti, Flavio Cermola, Marina DellaGreca, Maria Rosaria Iesce, \\ Lucio Previtera, Rosalia Sferruzza, and Fabio Temussi
}

UdR Napoli 4 INCA, Dipartimento di Scienze Chimiche, Università di Napoli Federico II, Complesso Universitario Monte S. Angelo, Via Cintia 21, 80126 Napoli, Italy

Correspondence should be addressed to Maria Rosaria Iesce; iesce@unina.it

Received 3 October 2013; Accepted 15 December 2013; Published 8 January 2014

Academic Editor: Zofia Stasicka

Copyright (C) 2014 Monica Passananti et al. This is an open access article distributed under the Creative Commons Attribution License, which permits unrestricted use, distribution, and reproduction in any medium, provided the original work is properly cited.

Irradiation of $N$-aryl $O$-aryl carbamates has been carried out in $\mathrm{H}_{2} \mathrm{O} / \mathrm{CH}_{3} \mathrm{CN}(1: 1 \mathrm{v} / \mathrm{v})$ solutions at $\lambda>290 \mathrm{~nm}$. When chlorine is on the $N$-aryl ring, halogen-substituted products are found. These photoproducts derive from the trapping of the intermediate radical cation by water and, even, by acetonitrile leading to phenols and $N$-arylacetamides (photo-Ritter products), respectively. Unsubstituted $N$-aryl carbamates slowly undergo photo-Fries reaction.

\section{Introduction}

Interaction of light with matter is one of the most important processes responsible for abiotic transformations of a xenobiotic in the environment, mainly in surface water [13]. Often the transformation process forms products that are more toxic than the parent compound [4-7]; hence, there is a need to consider transformation products during the environmental risk assessment process [8]. Although the photochemical behaviour of a molecule depends on the presence of peculiar functional groups, given the heterogeneity and, often, the structural complexity of these pollutants, it is frequently difficult to predict or rationalize their photochemical behavior. Carbamate function is present in a wide number of biologically active compounds. In particular, carbamate pesticides are an important group which are widely used through the world [9]. Although weak, carbamates exhibit absorption of radiation present in sunlight $(>290 \mathrm{~nm})$, and this requires the understanding of their photochemical behaviour [10]. The most general photochemical event, mainly observed in $O$-aryl derivatives, leads to rearranged products, via photoFries reaction and/or fragmentation $[10,11]$. Less frequent is this type of photorearrangement in $N$-aryl carbamates $[12,13]$. Recently, we studied the photochemical reactivity of two carbamate herbicides, chlorpropham, and phenisopham (Scheme 1) [14].

Irradiation of phenisopham in aqueous solution at $310 \mathrm{~nm}$ led to photo-Fries rearranged products involving the cleavage of $\mathrm{O}$-aryl $\mathrm{N}$-aryl carbamate function. As observed in other cases [12], the $\mathrm{O}$-alkyl $\mathrm{N}$-aryl carbamate was unreactive, and this result was also found in the irradiation of chlorpropham. In the latter case the $N$-aryl moiety reacted and gave isopropyl 3-hydroxycarbanilate by photosubstitution of aryl chlorine with a hydroxyl group [12, 14]. For the two pesticides different phototransformations were observed [14]. These results induced us to gain more information about the photochemical reactivity of $\mathrm{N}$-aryl $\mathrm{O}$-aryl carbamates that combine functions present in the pesticides examined. In particular, we prepared six model compounds 1 (Figure 1) and focused our attention on the photoproducts formation in aqueous solution $\left(\mathrm{H}_{2} \mathrm{O} / \mathrm{CH}_{3} \mathrm{CN} 1: 1 \mathrm{v} / \mathrm{v}\right.$ to have clear solutions) under UVB irradiation $(>300 \mathrm{~nm})$ in order that our investigation may be more relevant to environmental studies. 


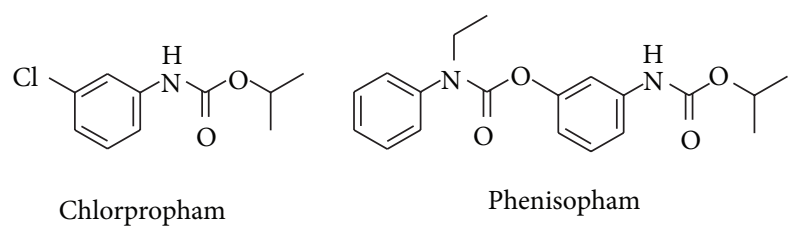

SCHEME 1<smiles>[R]c1ccc(N([R])C(=O)Oc2ccccc2)cc1[R]</smiles>

1

\begin{tabular}{|c|c|c|c|}
\hline & $\mathrm{R}^{1}$ & $\mathrm{R}^{2}$ & $\mathrm{R}^{3}$ \\
\hline $\mathbf{a}$ & $\mathrm{H}$ & $\mathrm{Cl}$ & $\mathrm{H}$ \\
\hline $\mathbf{b}$ & $\mathrm{Et}$ & $\mathrm{Cl}$ & $\mathrm{H}$ \\
\hline $\mathbf{c}$ & $\mathrm{H}$ & $\mathrm{H}$ & $\mathrm{Cl}$ \\
\hline $\mathbf{d}$ & $\mathrm{Et}$ & $\mathrm{H}$ & $\mathrm{Cl}$ \\
\hline $\mathbf{e}$ & $\mathrm{H}$ & $\mathrm{H}$ & $\mathrm{H}$ \\
\hline $\mathbf{f}$ & $\mathrm{Et}$ & $\mathrm{H}$ & $\mathrm{H}$ \\
\hline
\end{tabular}

FIGURE 1: Synthetic carbamates investigated.

\section{Materials and Methods}

2.1. Samples and Reagents. Aniline, 3-chloroaniline, 4-chloroaniline, and $N$-ethylaniline were purchased by Alfa Aesar. 3-Chloro- $N$-ethylaniline, 4-chloro- $N$-ethylaniline, and phenyl chloroformate were purchased by Sigma-Aldrich. All chemicals were used without further purification.

Milli-Q water (Millipore) was used to prepare aqueous solutions. Acetonitrile was of HPLC grade (Sigma-Aldrich).

2.2. Analytical Instruments. HPLC experiments were carried out on an Agilent 1100 HPLC system, equipped with an UV detector (set at $230 \mathrm{~nm}$ ), using a RP-18 column (Gemini, $5 \mu \mathrm{m}, 110 \mathrm{~A}, 250 \times 4.6 \mathrm{~mm})$. A mixture of $\mathrm{A}\left(\mathrm{H}_{2} \mathrm{O}\right.$ containing $1 \%$ formic acid)/B $\left(\mathrm{CH}_{3} \mathrm{CN}\right) 1: 1(\mathrm{v} / \mathrm{v})$ was used as mobile phase at a constant flow rate of $0.8 \mathrm{~mL} / \mathrm{min}$. Analytical and preparative TLC was made on Kieselgel $60 \mathrm{~F}_{254}$ plates with $0.2 \mathrm{~mm}$ and 0.5 or $1 \mathrm{~mm}$ layer thickness, respectively (Merck).

Proton NMR spectra were recorded on a Varian Inova500 instrument operating at $499.6 \mathrm{MHz}$ and referenced with deuterated solvents $\left(\mathrm{CDCl}_{3}\right)$. Electronic impact mass spectra (EI-MS) were obtained with a GC-MS QP5050A (Shimadzu) equipped with a $70 \mathrm{eV}$ EI detector. UV-Vis spectra were recorded with a Varian Cary $300 \mathrm{UV}$-Vis spectrophotometer. Melting point determinations were performed by a Gallenkamp melting point apparatus.

2.3. Synthesis of Diaryl Carbamates 1. In a typical experimental procedure, to a solution of each aniline $(15 \mathrm{mmol})$ in dry dichloromethane $(26 \mathrm{~mL}), 1.6 \mathrm{~mL}$ of phenyl chloroformate $(13 \mathrm{mmol})$ was added dropwise. The mixture was stirred at $0^{\circ} \mathrm{C}$ for $1 \mathrm{~h}$ and then it was kept at room temperature for $30 \mathrm{~min}$. The reaction mixture was neutralized with a saturated solution of sodium hydrogen carbonate and extracted with $\mathrm{CH}_{2} \mathrm{Cl}_{2}(3 \times 50 \mathrm{~mL})$. The combined organic layers were washed with brine, dried with anhydrous sodium sulfate, filtered and evaporated under reduced pressure. The residue was purified by silica gel column chromatography using light petroleum/diethyl ether $7: 3 \mathrm{v} / \mathrm{v}$ (compounds 1c and le were purified using light petroleum/EtOAc $7: 3$ and $9: 1 \mathrm{v} / \mathrm{v}$, resp.) to give carbamic compounds 1 with yields generally $>95 \%$. Products 1a, 1c, 1e [15], and 1f [16] were identified by comparison of their NMR spectra with those reported in the literature. The new products $\mathbf{1 b}$ and $\mathbf{1 d}$ were characterized on the basis of their spectral data.

Phenyl N-3-Chlorophenyl-N-ethylcarbamate (1b). Oil; EI-MS $m / z 275,182,153 ; \mathrm{UV} \lambda_{\max }\left(\mathrm{H}_{2} \mathrm{O} / \mathrm{CH}_{3} \mathrm{CN} 1 / 1\right) \mathrm{nm} 236$ $(\log \varepsilon 3.7) ;{ }^{1} \mathrm{H}$ NMR $\left(\mathrm{CDCl}_{3}\right) \delta$ 7.36-7.17 (m, overlapped signals, 9H), 3.83 (br q, 2H), 1.25 (br t, 3H).

Phenyl N-4-Chlorophenyl-N-ethylcarbamate (1d). mp 75.9$76.7^{\circ} \mathrm{C}$ (hexane/ethyl acetate); EI-MS $m / z$ 275, 182, 153; UV $\lambda_{\max }\left(\mathrm{H}_{2} \mathrm{O} / \mathrm{CH}_{3} \mathrm{CN} 1 / 1\right) \mathrm{nm} 238(\log \varepsilon 4.1) ;{ }^{1} \mathrm{H} \mathrm{NMR}\left(\mathrm{CDCl}_{3}\right)$ $\delta 7.38-7.25(\mathrm{~m}$, overlapped signals, $6 \mathrm{H}), 7.18(\mathrm{t}, J=7.3 \mathrm{~Hz}, 1 \mathrm{H})$, 7.10 (br s, 2H), 3.81 (br q, 2H), 1.23 (br t, 3H).

2.4. Photolysis Experiments. Irradiation was conducted in a Helios Italquartz multirays merry-go-round photoreactor equipped with six $15 \mathrm{~W}$ UV-B lamps with a maximal output at ca. $310 \mathrm{~nm}\left(1 \mathrm{~mW} \mathrm{~cm}^{-2}\right)$. Samples were irradiated in quartz tubes $(20 \times 1 \mathrm{~cm}, 25 \mathrm{~mL}) .1 \times 10^{-3} \mathrm{M}$ solutions of each carbamate 1 (50-90 mg) in $\mathrm{H}_{2} \mathrm{O} / \mathrm{CH}_{3} \mathrm{CN} 1: 1 \mathrm{v} / \mathrm{v}$ were irradiated and analyzed by HPLC and ${ }^{1} \mathrm{H}$ NMR at different times. The irradiation experiments were not stopped until starting compound was degraded at least for $20-30 \%$. The content of all tubes was collected and evaporated. The residue was analyzed by ${ }^{1} \mathrm{H}$ NMR and then chromatographed using light petroleum/ $\mathrm{Et}_{2} \mathrm{O} 6: 4 \mathrm{v} / \mathrm{v}$. Percentages of photoproducts in the irradiation mixtures were deduced by integration of isolated NMR signals and confirmed by chromatography. Compounds 2a [17] and 5c (=1e) [15] were identified by comparison of their NMR spectra with those reported in the literature while compounds $2 \mathrm{c}, 3 \mathrm{c}, \mathbf{8 f}, \mathbf{9 f}$, and 4hydroxybenzoic acid (7) were identified by comparison of their proton NMR spectra with those of authentic samples (Aurora Building Blocks and Aldrich).

\subsection{Spectroscopic Data for New Photoproducts}

Phenyl N-3-Acetamidophenylcarbamate (3a). Oil; EI-MS $m / z$ 270, 176, 134, 94; UV $\lambda_{\max }\left(\mathrm{H}_{2} \mathrm{O} / \mathrm{CH}_{3} \mathrm{CN} 1 / 1\right) \mathrm{nm} 228(\log \varepsilon$ 3.8); ${ }^{1} \mathrm{H} \mathrm{NMR}\left(\mathrm{CDCl}_{3}\right) \delta 7.75$ (br s, $\left.1 \mathrm{H}\right), 7.39(\mathrm{t}, J=7.9 \mathrm{~Hz}$, $2 \mathrm{H}), 7.29-7.22(\mathrm{~m}, 4 \mathrm{H}), 7.18$ (d, $J=7.5 \mathrm{~Hz}, 3 \mathrm{H}), 7.04$ (br s, $1 \mathrm{H}$ ), $2.16(\mathrm{~s}, 3 \mathrm{H})$.

Phenyl N-Ethyl-N-3-hydroxyphenylcarbamate (2b). Oil; EIMS $m / z$ 257, 164, 136; UV $\lambda_{\max }\left(\mathrm{H}_{2} \mathrm{O} / \mathrm{CH}_{3} \mathrm{CN} 1 / 1\right) \mathrm{nm} 275$ $(\log \varepsilon 3.4) ;{ }^{1} \mathrm{H} \mathrm{NMR}\left(\mathrm{CDCl}_{3}\right) \delta 7.38(\mathrm{t}, J=7.6 \mathrm{~Hz}, 2 \mathrm{H}), 7.23(\mathrm{t}$, $J=8.0 \mathrm{~Hz}, 1 \mathrm{H}), 7.30(\mathrm{t}, J=7.3 \mathrm{~Hz}, 1 \mathrm{H}), 7.10(\mathrm{~d}, J=4.5 \mathrm{~Hz}, 2 \mathrm{H})$, $6.87(\mathrm{~d}, J=7.9 \mathrm{~Hz}, 1 \mathrm{H}), 6.78(\mathrm{~s}, 1 \mathrm{H}), 6.72(\mathrm{~d}, J=7.8 \mathrm{~Hz}, 1 \mathrm{H})$, 3.80 (br q, $2 \mathrm{H}), 1.24$ (br t, $3 \mathrm{H})$.

Phenyl N-3-Acetamidophenyl-N-ethylcarbamate (3b). Oil; EIMS $m / z 298,205,177,135$; UV $\lambda_{\max }\left(\mathrm{H}_{2} \mathrm{O} / \mathrm{CH}_{3} \mathrm{CN}\right.$ 1/1) nm 275 (log $\varepsilon$ 3.2), $244(\log \varepsilon 4.0) ;{ }^{1} \mathrm{H} \mathrm{NMR}\left(\mathrm{CDCl}_{3}\right) \delta$ 7.61 (s, $1 \mathrm{H}), 7.52$ (s, 1H), 7.33-7.29 (m, overlapped signals, $4 \mathrm{H}$ ), 


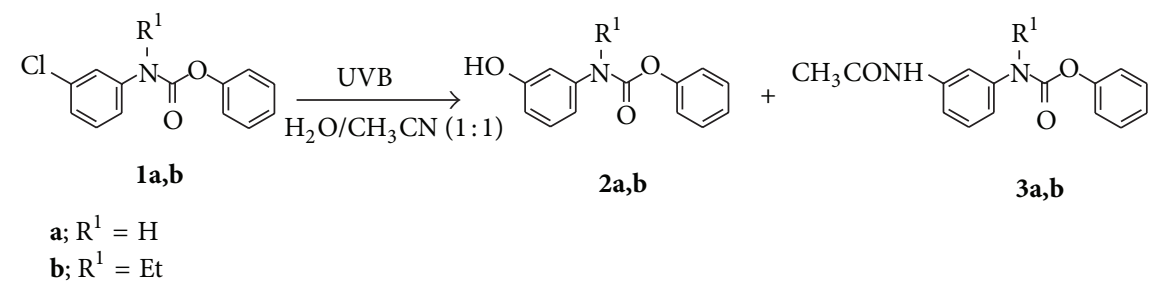

FIGURE 2: Irradiation of compounds $\mathbf{1 a}$ and $\mathbf{1 b}$.

7.16 (t, $J=7.1 \mathrm{~Hz}, 1 \mathrm{H}), 7.10$ (br s, 2H), 7.04 (d, $J=7.2 \mathrm{~Hz}, 1 \mathrm{H})$, 3.81 (br q, 2H), 2.12 (s, 3H), 1.24 (br t, 3H).

Phenyl N-4-Acetamidophenyl-N-ethylcarbamate (3d). mp 156.6-159.0 ${ }^{\circ} \mathrm{C}$ (chloroform/methanol); EI-MS $m / z$ 298, 205, 177, 135; UV $\lambda_{\max }\left(\mathrm{H}_{2} \mathrm{O} / \mathrm{CH}_{3} \mathrm{CN} 1 / 1\right) \mathrm{nm} 250(\log \varepsilon 10.2) ;{ }^{1} \mathrm{H}$ NMR (CD $\mathrm{OD}): \delta 7.63(\mathrm{~d}, J=9.0 \mathrm{~Hz}, 4 \mathrm{H}), 7.34$ (br m, $2 \mathrm{H})$, 7.31 (d, $J=9.3 \mathrm{~Hz}, 2 \mathrm{H}), 7.20$ (br m, 1H), 7.05 (br s, $1 \mathrm{H}), 4.10$ (q, $J=7.1 \mathrm{~Hz}, 2 \mathrm{H}), 2.16(\mathrm{~s}, 3 \mathrm{H}), 1.24(\mathrm{t}, J=7.1 \mathrm{~Hz}, 3 \mathrm{H})$.

\section{Results and Discussion}

Phenyl meta-chlorophenyl carbamates $\mathbf{1 a}, \mathbf{b}$ can be distinguished by the presence of chlorine on the $N$-aryl group (function present in chlorpropham) and by the different substitution on nitrogen (function present in phenisopham) (Figure 2). Irradiation was followed by HPLC and interrupted at a conversion of ca. 20-40\%. Compound la was converted for $30 \%$ after $2 \mathrm{~h}$. Preparative TLC chromatography led to isolation of unreacted la (71\%), hydroxy derivative 2a (14\%), and a product $(15 \%)$ to which structure $3 \mathbf{a}$ was assigned by spectroscopic means (Figure 2). In particular, mass spectrum of 3a showed the absence of isotopic chlorine peaks and a peak at $270 \mathrm{~m} / z$ indicating the presence of another nitrogen. Moreover, in the proton spectrum a typical singlet at $\delta 2.16$ associated to a methyl linked to a carbonyl group and in the ${ }^{13} \mathrm{C}$ NMR a quaternary low-field signal at $\delta 168.4$ indicated the substitution of chlorine with $\mathrm{NHCOCH}_{3}$ group. The percentages of photoproducts were deduced by integration of selected signals in the proton NMR of the irradiation mixture and confirmed by chromatography.

Similar results were obtained starting from $\mathrm{N}$-ethyl derivative $\mathbf{1} \mathbf{b}$ which, however, required a longer irradiation time. After $14 \mathrm{~h}$ of irradiation $\mathbf{1 b}$ was $78 \%$ in addition to $\mathbf{2 b}(10 \%)$ and $\mathbf{3 b}$ (12\%) (Figure 2).

The different photodegradation rates of $\mathbf{1 a}$ and $\mathbf{1 b}$ could be due to the different intensities of UV absorptions. Indeed, as shown in Figure 3, the $N$-monosubstituted carbamate la exhibits stronger absorption bands than the $N$-ethyl analogue $\mathbf{l b}$, even in 280-300 $\mathrm{nm}$ range.

Despite the presence of the $\mathrm{O}$-aryl moiety, the photoinduced carbamate cleavage was not observed and only dehalogenated products, phenols $\mathbf{2} \mathbf{a}, \mathbf{b}$, and acetamides $\mathbf{3 a} \mathbf{b}$, were isolated. Photohydrolysis to give phenols is the most frequent photoreaction of halogenated aromatic compounds in water and is reported to occur by a photoionization

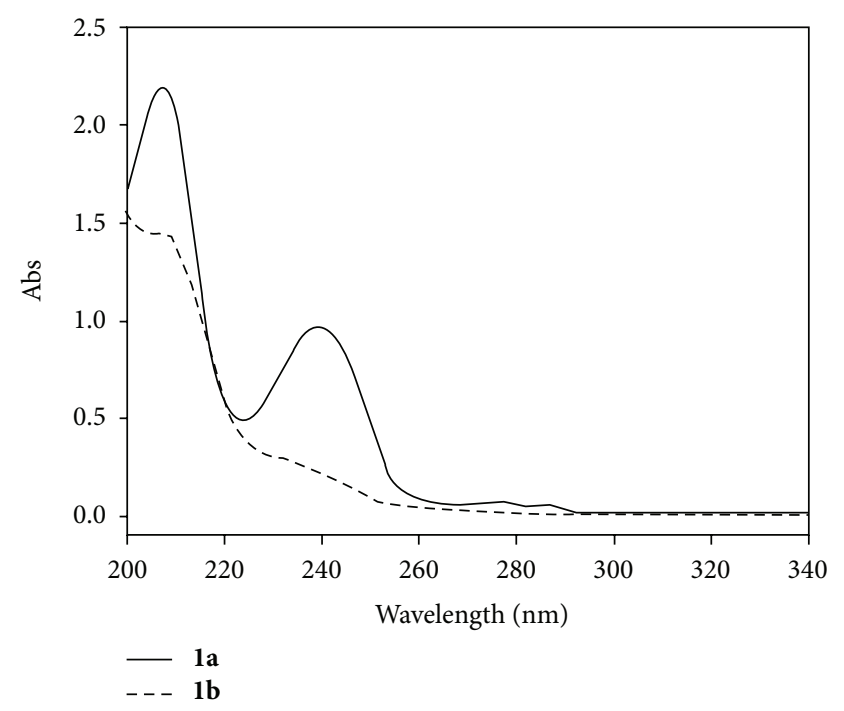

FIgURE 3: UV-vis spectra of $\mathbf{1 a}$ and $\mathbf{1 b}$ in $\mathrm{H}_{2} \mathrm{O} / \mathrm{CH}_{3} \mathrm{CN}(1: 1 \mathrm{v} / \mathrm{v})(5$ $\left.\times 10^{-5} \mathrm{M}\right)$.

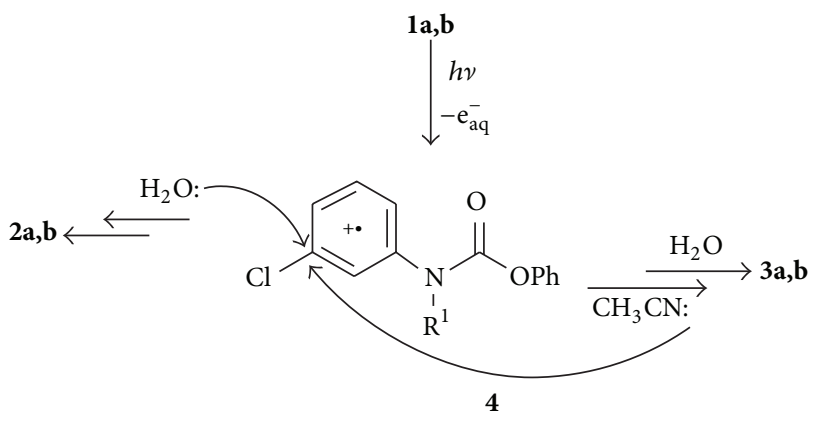

(a) Photohydrolysis

(b) Photo-Ritter

Figure 4: Suggested pathways for photoproducts $\mathbf{2 a , b}$, and 3a,b formation.

process, favoured by the medium, [18, 19]. Accordingly, phenols $2 \mathbf{a}, \mathbf{b}$ should derive from the radical cation 4 that can be trapped by water (pathway a, Figure 4) $[18,19]$. The attack on the radical cation 4 by nitrogen of acetonitrile and subsequent hydrolysis should give compounds $\mathbf{3 a}, \mathbf{b}$ (pathway b, Figure 4). Compounds 2 and 3 can also be formed by nucleophilic solvent trapping of an aryl cation deriving from homolysis, followed by in-cage electron transfer [18]. 


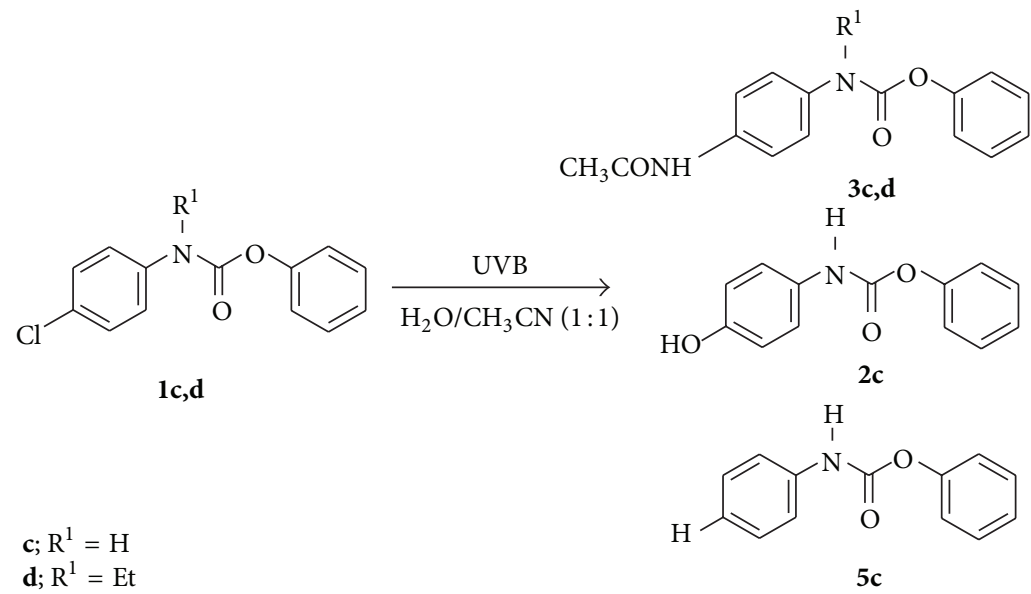

Figure 5: Irradiation of compounds $\mathbf{1 c}$ and $\mathbf{1 d}$.

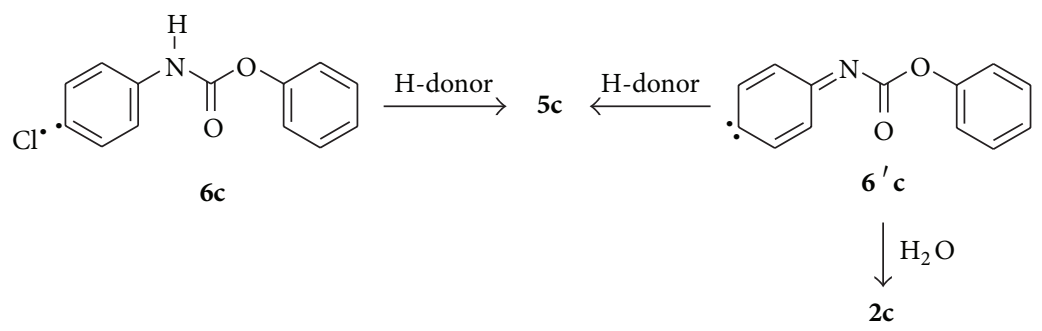

FIGURE 6: Suggested intermediates for the photoproducts $5 \mathrm{c}$ and $2 \mathrm{c}$.

Acetamides as 3 have been found by irradiating halogenated compounds [20] or dienes [21] in aqueous acetonitrile, and it has been shown that this solvent is involved in their formation in a so-called photo-Ritter reaction $[20,21]$. Control experiments showed that, as expected, the amounts of photo-Ritter products $\mathbf{3 a}, \mathbf{b}$ decreased with increasing the water content in the reaction medium. For example, amount of $3 \mathbf{a}$ decreased from $15 \%$ to $5 \%$ when the acetonitrile amount decreased from $50 \%$ to $30 \%$. It is interesting to note that the conversion of $\mathbf{1 c}$ is accelerated ( $30 \%$ after only $1 \mathrm{~h}$ ) by water increase in the reaction medium, because the first photochemical event is the photoionization that is favoured by the aqueous medium.

Halogen-substitution reactions were also observed for para-chloroderivatives $\mathbf{1 c}, \mathbf{d}$ (Figure 5). After $2 \mathrm{~h} \mathbf{1 c}$ was almost completely degraded. However, compounds $2 \mathrm{c}$ and $3 \mathrm{c}$ were recovered in small amounts. The main product was a dechlorinated compound, the diphenyl carbamate 5c $(=\mathbf{l e}$, see Figures 5 and 6), in addition to a significant amount of polymeric material. After $2 \mathrm{~h}$ the yields were 1c (10\%), 2c (8\%), 3c (15\%) 5c (34\%), and polymeric material (ca. 33\%). As $\mathbf{1 b}, N$-ethyl derivative $\mathbf{1 d}$ was converted slowly and the sole product identified was acetamide $\mathbf{3 d}$ (after $10 \mathrm{~h} \mathbf{1 d}(71 \%), \mathbf{3 d}$ (29\%)) (Figure 5).

Photoreduction has been sometimes observed in the irradiation of halogenated aromatic compounds, mainly in para-substituted derivatives [18]. A radical mechanism has been proposed so that formation of $5 \mathrm{c}$ should occur probably via intermediate $\mathbf{6 c}$ (Figure 6). It is also plausible that, as suggested in similar cases [19], a carbene intermediate $\mathbf{6}^{\prime} \mathbf{c}$ is involved in the formation of $5 \mathrm{c}$ and also $2 \mathrm{c}$, thus justifying the absence of similar compounds for 1d (Figure 6).

Unsubstituted $N$-aryl compounds le and 1f exhibited high photostability. After $42 \mathrm{~h}<5 \%$ of le was converted and only hydroxybenzoic acid 7 was identified by HPLC (Figure 7). Differently, from what was observed for the couples $\mathbf{1 a}, \mathbf{b}$ and $\mathbf{1 c}, \mathbf{d}, N$-ethyl derivative $\mathbf{1 f}$ appeared more photoreactive than its $\mathrm{NH}$ analogue 1e. Indeed, after the same irradiation time $(42 \mathrm{~h})$ it was converted for $24 \%$ and chromatography gave if $(75 \%)$, the acid 7 (18\%), the parabenzamide $8 f(6 \%)$ and the ortho-benzamide $9 f$ (trace) (Figure 7).

Structures $8 \mathrm{f}$ and $\mathbf{9 f}$ derive by a typical photo-Fries rearrangement. As well known [22], this reaction occurs via homolytic cleavage of the carbonyl-heteroatom single bond giving the caged radical pair 10 (Figure 8). In-cage recombination in para and/or ortho-position affords the acyl migration products as $\mathbf{8 f}$ and $\mathbf{9 f}$, respectively.

para-Hydroxybenzoic acid 7 could be formed by hydrolysis of $\mathbf{8}$ due to the long water contact for the prolonged irradiation. Stabilization of radicals by substitution could account for the breakage less difficult in $N$-ethyl compound lf than le.

\section{Conclusions}

Our results show that the $N$-aryl $O$-aryl substitution is not a sufficient condition to have a photo-induced breaking of 


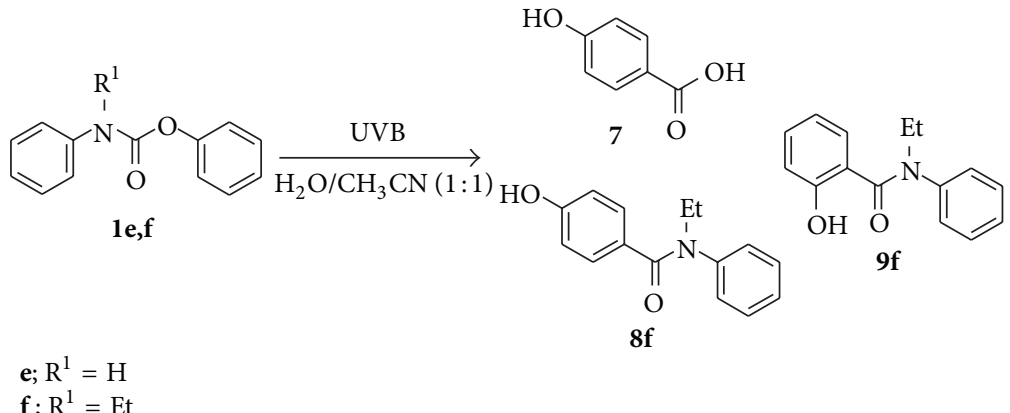

FIGURE 7: Irradiation of compounds le and $\mathbf{l f}$.

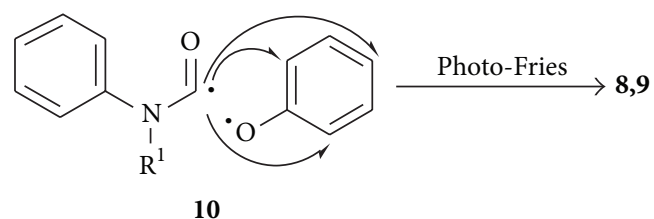

Figure 8: Suggested pathways for the photoproducts 8 and 9 formation.

the carbamate bond. This process is completely overcome in the presence of other photosensitive functions as chlorine on the $N$-aryl ring. In the latter case photosolvolysis or photoreduction occurs depending on the halogen position on the ring.

The $N$-substitution does not affect the product formation but influences the degradation rate due to radical stabilization or to a lower absorption of UVB radiation.

An interesting result is the obtaining of the photo-Ritter products derived from the nucleophilic trapping of radical cations by acetonitrile. We proved that when the pesticide chlorpropham was irradiated in $\mathrm{H}_{2} \mathrm{O} /$ acetonitrile $1: 1 \mathrm{v} / \mathrm{v}$, a product with similar spectroscopic data as $\mathbf{3 c , d}$ was formed.

Acetonitrile is generally used in environmental investigation as cosolvent to have clear aqueous solutions of compounds slightly soluble in water. The U.S. Environmental Protection Agency in the Fate and Transformation of chemicals Test Guidelines [23] suggests that the use of acetonitrile should be preferably not exceeding $1 \%$, but cosolvent percentages up to $10 \%$ are allowed. Hence, to avoid mistakes, characterization of photoproducts is necessary.

\section{Conflict of Interests}

The authors declare that there is no conflict of interests regarding the publication of this paper.

\section{References}

[1] H. Neilson and A. S. Allard, Environmental Degradation and Transformation of Organic Chemicals, CRC Press, Boca Raton, Fla, USA, 2008.

[2] A. Albini and E. Fasani, Drugs. Photochemistry and Photostability, The Royal Society of Chemistry, Cambridge, UK, 1998.
[3] P. Boule, Environmental Photochemistry, Springer, Berlin, Germany, 1999.

[4] W. Klöpffer, "Photochemical degradation of pesticides and other chemicals in the environment: a critical assessment of the state of the art," Science of the Total Environment, vol. 123-124, pp. 145-159, 1992.

[5] D. W. Kolpin, E. M. Thurman, and S. M. Linhart, "The environmental occurrence of herbicides: the importance of degradates in ground water," Archives of Environmental Contamination and Toxicology, vol. 35, no. 3, pp. 385-390, 1998.

[6] M. R. Iesce, M. Della Greca, F. Cermola, M. Rubino, M. Isidori, and L. Pascarella, "Transformation and ecotoxicity of carbamic pesticides in water," Environmental Science and Pollution Research, vol. 13, no. 2, pp. 105-109, 2006.

[7] M. Isidori, A. Parrella, P. Pistillo, and F. Temussi, "Effects of ranitidine and its photoderivatives in the aquatic environment," Environment International, vol. 35, no. 5, pp. 821-825, 2009.

[8] C. J. Sinclair and A. B. A. Boxall, "Assessing the ecotoxicity of pesticide transformation products," Environmental Science and Technology, vol. 37, no. 20, pp. 4617-4625, 2003.

[9] C. Tomlin, Pesticides and Agricultural Chemicals, GWA Milne Gower Publishing, Aldershot, UK, 2001.

[10] H. D. Burrows, M. Canle L, J. A. Santaballa, and S. Steenken, "Reaction pathways and mechanisms of photodegradation of pesticides," Journal of Photochemistry and Photobiology B, vol. 67, no. 2, pp. 71-108, 2002.

[11] P. J. Silk, G. P. Semeluk, and I. Unger, "The photoreactions of carbamate insecticides," Phytoparasitica, vol. 4, no. 1, pp. 51-63, 1976.

[12] P. Boule, L. Meunier, F. Bonnemoy, A. Boulkamh, A. Zertal, and B. Lavedrine, "Direct phototransformation of aromatic pesticides in aqueous solution," International Journal of Photoenergy, vol. 4, no. 2, pp. 69-78, 2002.

[13] J. E. Herweh and C. E. Hoyle, "Photodegradation of some alkyl $\mathrm{N}$-arylcarbamates," Journal of Organic Chemistry, vol. 45, no. 11, pp. 2195-2201, 1980.

[14] M. Passananti, F. Temussi, M. R. Iesce et al., "Chlorproham and phenisopham: phototransformation and ecotoxicity of carbamates in the aquatic environment," Environmental Science: Processes \& Impacts, 2013.

[15] A. B. Shivarkar, S. P. Gupte, and R. V. Chaudhari, "Carbamate synthesis via transfunctionalization of substituted ureas and carbonates," Journal of Molecular Catalysis A, vol. 223, no. 1-2, pp. 85-92, 2004.

[16] S. Imori and H. Togo, "Efficient demethylation of N,Ndimethylanilines with phenyl chloroformate in ionic liquids," Synlett, no. 16, pp. 2629-2632, 2006. 
[17] S. Akita, N. Umezawa, and T. Higuchi, "On-bead fluorescence assay for serine/threonine kinases," Organic Letters, vol. 7, no. 25, pp. 5565-5568, 2005.

[18] L. Schutt and N. J. Bunce, "Photodehalogenation of aryl halides," in CRC Handbook of Organic Photochemistry and Photobiology, W. Horspool and F. Lenci, Eds., pp. 38-31, CRC Press, Boca Raton, Fla, USA, 2004.

[19] P. Boule, K. Othmen, C. Richard, B. Szczepanik, and G. Grabner, "Phototransformation of halogenoaromatic derivatives in aqueous solution," International Journal of Photoenergy, vol. 1, no. 1, pp. 1-6, 1999.

[20] N.-M. Bi, M.-G. Ren, and Q.-H. Song, "Photo-ritter reaction of arylmethyl bromides in acetonitrile," Synthetic Communications, vol. 40, no. 17, pp. 2617-2623, 2010.

[21] H. Ishii, T. Hirano, S. Maki, H. Niwa, and M. Ohashi, "A novel, stereoselective photo-ritter reaction of 1,1-diphenyl-1,6heptadiene via photoinduced electron transfer reaction," Tetrahedron Letters, vol. 39, no. 18, pp. 2791-2792, 1998.

[22] M. A. Miranda and F. Galindo, "Photo-fries reaction and related processes.," in CRC Handbook of Organic Photochemistry and Photobiology, W. Horspool and F. Lenci, Eds., pp. 42-1-42-11, CRC Press, Boca Raton, Fla, USA, 2004.

[23] Spectroscopic data of isopropyl N-3-acetamidophenylcarbamate: EI-MS m/z 236, 194, 177, 152, 108; UV $\lambda_{\max }\left(\mathrm{H}_{2} \mathrm{O} / \mathrm{CH}_{3} \mathrm{CN} 1: 1 \mathrm{v} / \mathrm{v}\right)$ $225 \mathrm{~nm}(\log 3.7), 280 \mathrm{~nm}(\log 2.7) ;{ }^{1} \mathrm{H}$ NMR $\left(500 \mathrm{MHz}, \mathrm{CDCl}_{3}\right)$ $\delta 7.65(\mathrm{~s}, 1 \mathrm{H}), 7.23(\mathrm{~d}, J=7.1 \mathrm{~Hz}, 2 \mathrm{H}), 7.15(\mathrm{br} \mathrm{s}, 1 \mathrm{H}), 7.11(\mathrm{~m}, 1 \mathrm{H})$, 6.56 (br s, 1H), 5.00 (sept, $J=6.3 \mathrm{~Hz}, 1 \mathrm{H}), 2.16$ (s, 3H), 1.30 (d, $J$ $=6.2 \mathrm{~Hz}, 6 \mathrm{H})$. 

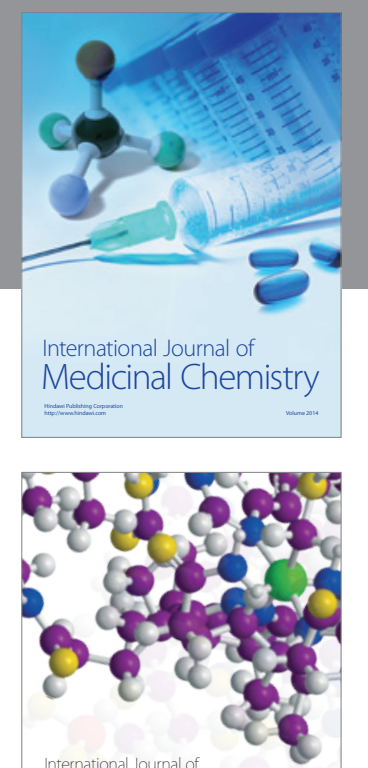

\section{Carbohydrate} Chemistry

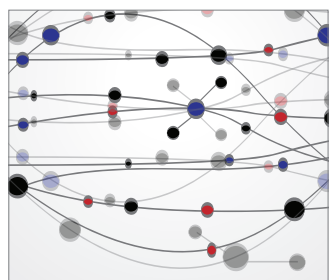

The Scientific World Journal
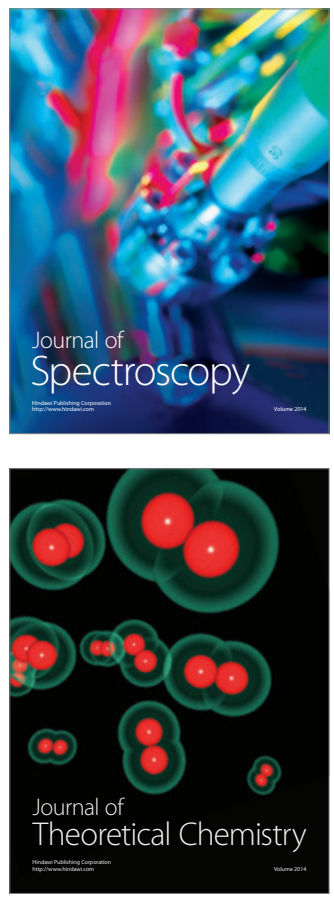
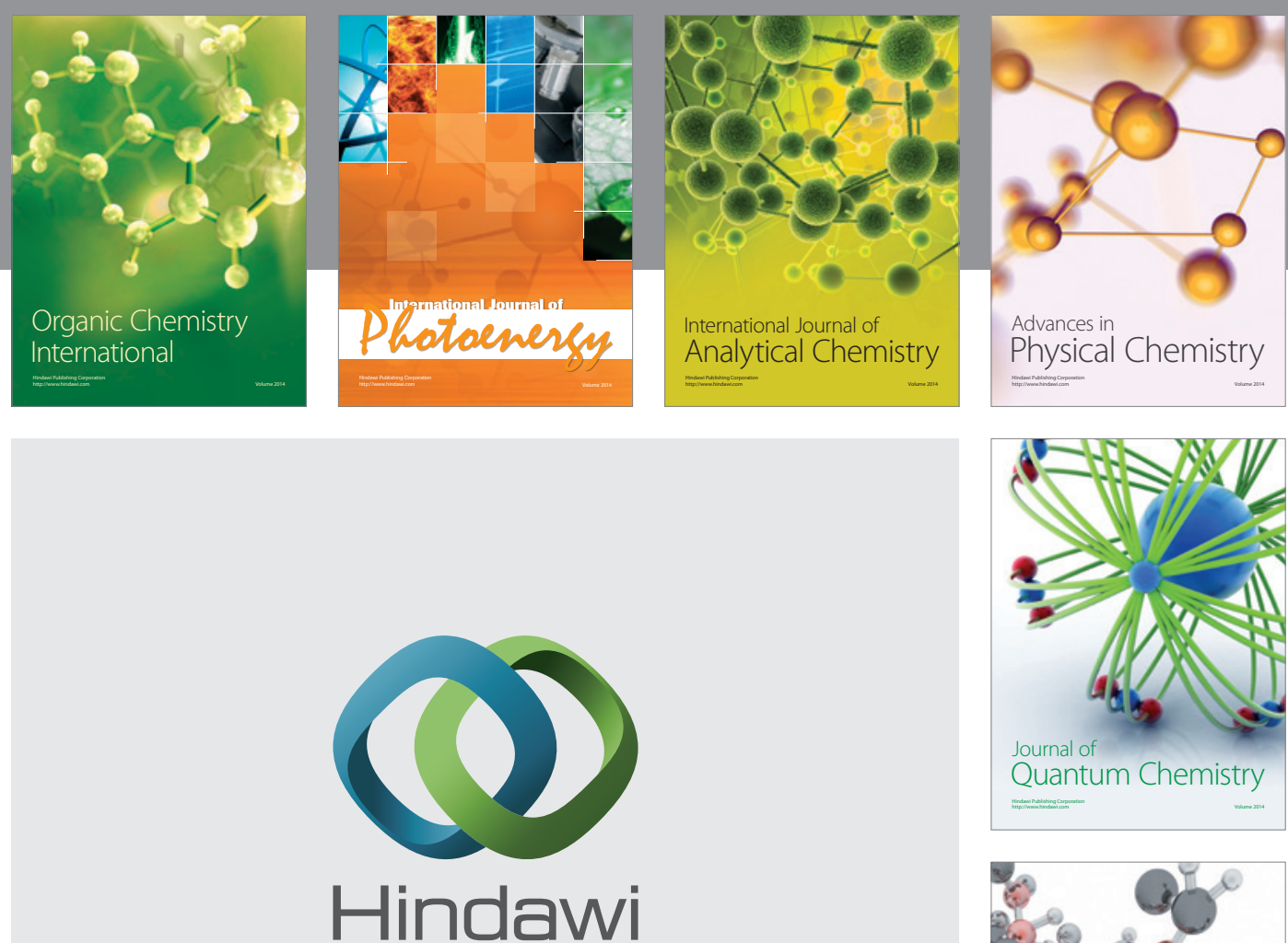

Submit your manuscripts at

http://www.hindawi.com

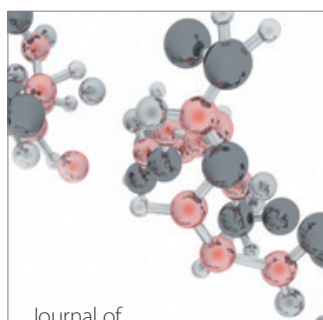

Analytical Methods

in Chemistry

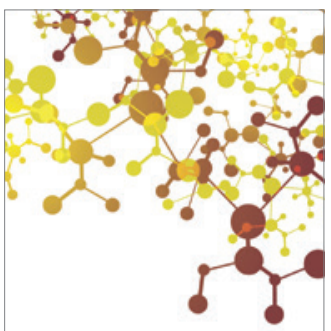

Journal of

Applied Chemistry

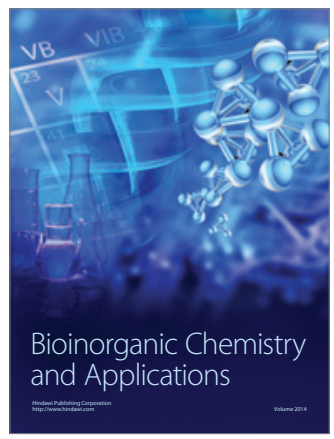

Inorganic Chemistry
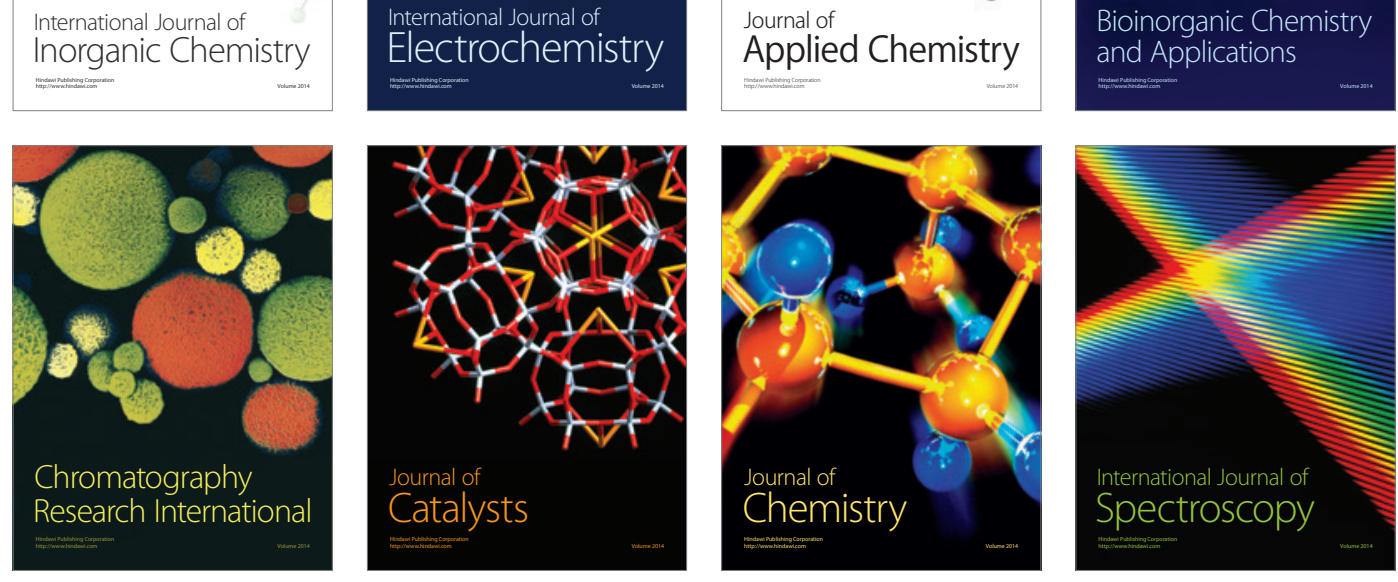